\title{
Record-breaking heat wave in southern China and delayed onset of South China Sea summer monsoon driven by the Pacific subtropical high
}

\author{
Kaiqiang Deng ${ }^{1,2} \cdot$ Song Yang ${ }^{1,3,4}$ - Dejun $\mathrm{Gu}^{5} \cdot$ Ailan $\mathrm{Lin}^{5} \cdot$ Chunhui $\mathrm{Li}^{5}$
}

Received: 21 October 2019 / Accepted: 5 March 2020 / Published online: 16 March 2020

(c) The Author(s) 2020

\begin{abstract}
We investigate a record-breaking heat wave in southern China (SC) and explore its association with the South China Sea (SCS) summer monsoon (SCSSM), using station observations and various reanalysis products. This heat wave event started in mid-May 2018 and persisted more than 15 days, when the maximum air temperature anomaly exceeded $6{ }^{\circ} \mathrm{C}$. Meanwhile, the onset of the SCSSM was extremely late in 2018, primarily due to the intrusion of easterly winds over the SCS. We show that the anomalous easterlies over the SCS associated with the delayed SCSSM could block the moisture transport from the tropical oceans to SC, which led to decreased rainfall, increased surface radiation, and elevated probability of heat wave in SC during May 2018. Further analysis reveals that both SC heat waves and SCSSM were significantly affected by the Pacific subtropical high (PSH). The westward extension of the PSH can hinder the establishment of SCSSM via inducing easterly anomalies over the SCS, which reduces SC rainfall and results in a drier surface condition. Moreover, the westward displacement of the PSH may cause anomalously high pressures, descending air motions, and divergent winds over SC, which triggers above-normal air temperatures that are conducive to the occurrences of SC heat waves. This study also underlines the importance of Eurasian planetary wave trains in bridging the upstream climate variability and the changes in PSH during boreal spring, which could be used to improve the intra-seasonal predictions of SC heat wave and SCSSM onset.
\end{abstract}

Keywords Southern China $\cdot$ Heat waves $\cdot$ South China Sea summer monsoon $\cdot$ Pacific subtropical high

\section{Introduction}

Heat wave, one of the most devastating weather disasters in the changing climate, is believed to have great impacts on ecosystem and human society (Meehl and Tebaldi 2004;

Song Yang

yangsong3@mail.sysu.edu.cn

1 School of Atmospheric Sciences, Sun Yat-sen University, 135 West Xingang Road, Guangzhou 510275, China

2 Regional Climate Group, Department of Earth Sciences, University of Gothenburg, Gothenburg, Sweden

3 Guangdong Province Key Laboratory for Climate Change and Natural Disaster Studies, Sun Yat-sen University, Guangzhou, China

4 Southern Marine Science and Engineering Guangdong Laboratory (Zhuhai), Zhuhai, Guangdong, China

5 Guangzhou Institute of Tropical and Marine Meteorology, CMA, Guangzhou, China
Coumou and Rahmstorf 2012; Deng et al. 2018a). Southern China (SC) experienced an exceptionally strong heat wave during May 2018, when 52 counties of Guangdong Province reported record-breaking air temperatures ranging from 33.1 to $38.7{ }^{\circ} \mathrm{C}$, including eight consecutive days when the maximum temperatures exceeded $35^{\circ} \mathrm{C}$ (Wang et al. 2018; Zhang et al. 2019). Although the increased frequency and strengthened intensity of SC heat waves have attracted more and more attention from climate research community (Sun et al. 2011; Wang et al. 2013; Chen et al. 2018), most of these studies focused on summer season. In contrast, the spatiotemporal evolution and physical mechanisms associated with SC heat waves in the boreal spring are not well understood.

Coinciding with the SC heat wave in late-spring 2018, the onset of the South China Sea (SCS) summer monsoon (SCSSM) was found to be long delayed in that year (Zhang and He 2018; Liu and Zhu 2019). The onset of the SCSSM is characterized by an abrupt wind transition from easterlies to westerlies and by a burst of deep convection over 
the central SCS (Kajikawa and Wang 2012). Climatologically the onset of SCSSM builds up in pentad 28, and the latest onset of the monsoon appears in pentad 34 (Wang et al. 2004). In 2018, the onset of SCSSM was established significantly late, in pentad 31 (early June).

The SC heat wave during spring 2018 started to disappear following the establishment of the 2018 SCSSM, which motivated us to study whether the occurrence of SC heat wave was related to the changes in SCSSM onset. Normally, the outbreak of the SCSSM marks the beginning of presummer rainy season, which brings plenty of wet and warm air from the tropical oceans to East Asia, triggers vigorous rainfall, and deceases insolation in SC during May (Ding et al. 2004). Inversely, an extremely delayed onset of the SCSSM may substantially weaken the transport of water vapor from the SCS to SC during May, leading to reduced rainfall, increased incoming radiation, and drier surface environment in SC (Wang et al. 2004; Kajikawa and Wang 2012; Li et al. 2016). In other words, an early-onset SCSSM may suppress the emergence of SC heat wave due to the rainy weather, while a delayed-onset SCSSM tends to provide a favorable surface environment for the breeding of SC heat wave. Thus, understanding the change in SCSSM onset and its correlation with SC heat wave is helpful to improve the predictions for SC extreme weather events. Therefore, a comprehensive examination on the statistical relationship and physical attribution associated with SC heat wave and SCSSM is needed.

In addition to understanding the linkage between SC heat wave and SCSSM, it is also important to understand the external drivers that modulate the relationship between SC heat wave and SCSSM. One of the most prominent factors involved may be the Pacific subtropical high (PSH), which was found to experience significantly westward extension during spring 2018 (Deng et al. 2018b, 2019a). The westward displacement of the PSH, on the one hand, leads to anomalously high pressure over East Asia, which may considerably increase the frequency and total days of heat waves in SC (Sun et al. 2011; Wang et al. 2013; Luo and Lau 2018). On the other hand, the westward movement of the PSH can result in strengthened anticyclone over the SCS, suppressing the convective activity over the SCS and prohibiting the onset of the SCSSM. Zhou et al. (2009) indicated that the PSH stretched continuously westward since the late 1970 s, partly due to the atmosphere's response to the observed Indian Ocean-western Pacific warming. In addition, Liu and Zhu (2019) suggested that the westward extension of the PSH be linked to mid-latitude planetary wave train. Therefore, it is of great interest to explore the external drivers responsible for the westward shift of the PSH and to understand how the change in PSH location influences SC heat wave and SCSSM onset.
This paper is organized as follows. In Sect. 2, we describe data sets and methods. In Sect. 3, we show the spatiotemporal features of SC heat wave and SCSSM during 2018. In Sect. 4, we explore the local and remote physical processes related to SC heat wave and SCSSM. Finally, a summary is given in Sect. 5.

\section{Data and methods}

\subsection{Data sets}

The daily $2 \mathrm{~m}$ maximum air temperature (Tmax) and precipitation data are collected from 86 weather stations within Guangdong Province (see Fig. 1), for the period from 01 Jan 1951 to $30 \mathrm{Sep} 2018$. The station data are provided by the Guangzhou Institute of Tropical and Marine Meteorology, China Meteorological Administration. We applied some conventional quality-control procedures, including checks for climatology, station, and regional outliers, to improve the data quality. For convenience, we mapped the station data to $0.1^{\circ} \times 0.1^{\circ}$ grid using the Cressman interpolation before computing and plotting.

To investigate the variations of large-scale atmospheric circulation and meteorological variables and their associations with SC heat wave and SCSSM onset, we also use the data sets of the ECMWF ERA-Interim (Dee et al. 2011) and NCEP-NCAR Reanalysis (Kalnay et al. 1996). The daily surface variables from the ERA-Interim include Tmax, net solar radiation, net thermal radiation, latent heat, and sensible heat, with a horizontal resolution of $1^{\circ} \times 1^{\circ}$ during 01 January 1979 to present. For the surface radiation and heat fluxes, a positive (negative) value means downward (upward) flux that the surface obtains (losses) energy. The variables from the NCEP-NCAR Reanalysis include horizontal wind, geopotential height, and specific humidity at multiple pressure levels, with a horizontal resolution of $2.5^{\circ}$ $\times 2.5^{\circ}$ during January 1948 to present. The monthly anomalies of surface temperature are obtained from the NOAA/ OAR/ESRL PSD, Boulder, Colorado, USA, via their website at https://www.esrl.noaa.gov/psd/, with a horizontal resolution of $2^{\circ} \times 2^{\circ}$ from January 1880 to present. The monthly Extended Reconstructed Sea Surface Temperature Version 4 (ERSSTv4; Huang et al. 2015), which is derived from the International Comprehensive Ocean-Atmosphere Dataset, has a resolution of $2^{\circ} \times 2^{\circ}$ and covers the period of 1854 to present.

\subsection{Measurements of heat wave, SCSSM, and PSH}

The intensity of heat wave can be measured by the temperature anomalies above the climatological and/or percentile-based threshold. The percentile threshold of $\mathrm{T}_{\max }$ 


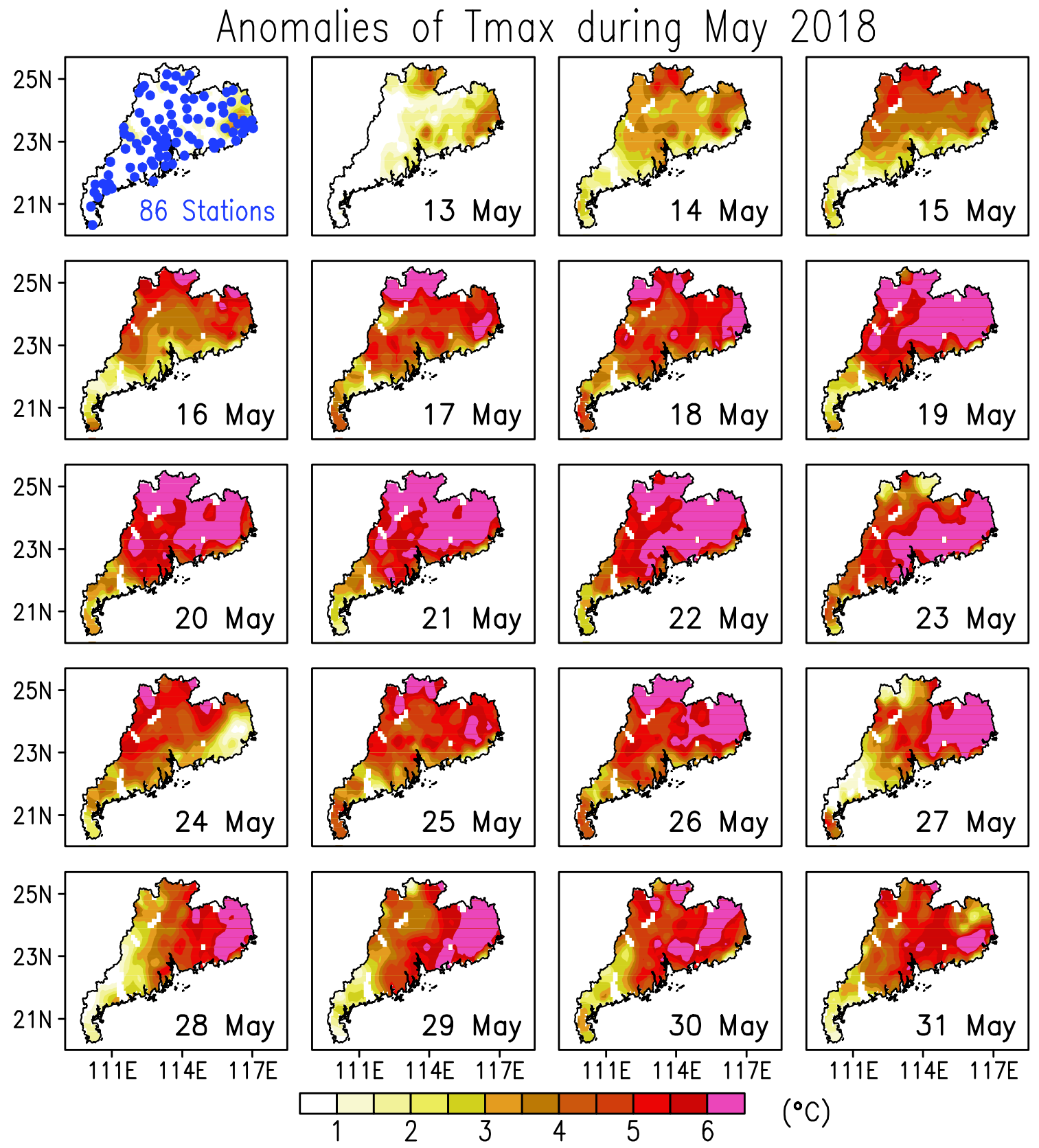

Fig. 1 Spatial patterns of maximum $2 \mathrm{~m}$ air temperature $\left(\mathrm{T}_{\max }\right)$ anomalies $\left({ }^{\circ} \mathrm{C}\right)$ during $12-31$ May 2018 after removing daily climatology $(1951-$ 2018). Blue dots in the first panel indicate 86 meteorological stations within Guangdong Province

on a specific date is determined by the 90 th percentile of Tmax for a total of 476 days $(68 \times 7$, the seven days corresponding to three days on either side of the target date) for the 68 years from 1951 to 2018 (Deng et al. 2019b). By moving the 7-day sampling window forward or backward, we can acquire consecutive threshold for each day.

We use a simple yet effective index to depict the onset of the SCSSM, which was proposed by Wang et al. (2004):
$U_{S C S S M}=U_{850}\left(5^{\circ} \mathrm{N}-15^{\circ} \mathrm{N}, 110^{\circ} \mathrm{E}-120^{\circ} \mathrm{E}\right)$

where $U_{850}$ indicates the $850-\mathrm{hPa}$ zonal wind averaged over the central SCS $\left(110^{\circ}-120^{\circ} \mathrm{E}, 5^{\circ}-15^{\circ} \mathrm{N}\right)$. This onset index can represent not only the sudden establishment of the tropical southwesterly monsoon over the SCS, but also the outbreak of the rainy season in the central-northern SCS. A common way to describe the west-east movement of the 
PSH is based on the longitude of the west end of a specific contour over the western Pacific (Yang and Sun 2005; Yang et al. 2017). Following this method, we computed the zonal location index of the PSH in May of 1951-2018, using the longitude of the west edge of $1500 \mathrm{gpm}$ contour at $850 \mathrm{hPa}$. Note that although the 500-hPa geopotential height has been widely used to identify the PSH, the western extent of the $\mathrm{PSH}$ at $850 \mathrm{hPa}$ exhibits great interannual variability ( $\mathrm{Lu}$ 2002). Moreover, we examined several other contours at 850 $\mathrm{hPa}$ using slightly different geopotential height values, and obtained very similar index time series, suggesting that the zonal location index for the PSH using such a method be relatively robust. A smaller value of the PSH index means that the PSH extends more westward, and vice versa.

Other methods used in this study include diagnostic analysis on wave activity flux (Takaya and Nakamura 2001), composite differences, and linear regression/correlation. The statistical significances of the composite and correlation results are tested by the Student's $t$ test.

\section{Spatiotemporal features of SC heat wave and SCSSM}

\subsection{A record-breaking heat wave in SC during May 2018}

We first present the evolution of daily Tmax anomalies during May 2018. As seen from Fig. 1, abnormally high air temperatures were observed over the entire Guangdong Province, which started in mid-May 2018 and sustained until early-June. The anomalously high air temperatures mainly existed in eastern and northern regions of the province, with a maximum air temperature anomaly of $6{ }^{\circ} \mathrm{C}$ above the climatology. Note that Guangdong Province is the most densely populated and economically advanced province in China, and thereby an extreme heat wave over the region could lead to more severe ecological impacts and larger economic losses.

Figure 2a displays the time series of Tmax averaged over the 86 stations for different years, its daily climatology, and corresponding 90th-percentile threshold. We can see that the Tmax increased rapidly during 10-15 May of 2018, while the climatological and 90th-percentile thresholds varied much more slowly in the same period. From mid-May to early-June 2018, an extreme heat wave can be identified through both climatological and 90th -percentile thresholds, when the Tmax was as high as $34{ }^{\circ} \mathrm{C}$ and exceeded the threshold for more than half a month. Figure $2 \mathrm{~b}$ presents the year-to-year variation of monthly Tmax in May of 1951-2018. Overall, the monthly mean Tmax shows a slowly increasing trend since 1980, which might be associated with the anthropogenic warming in
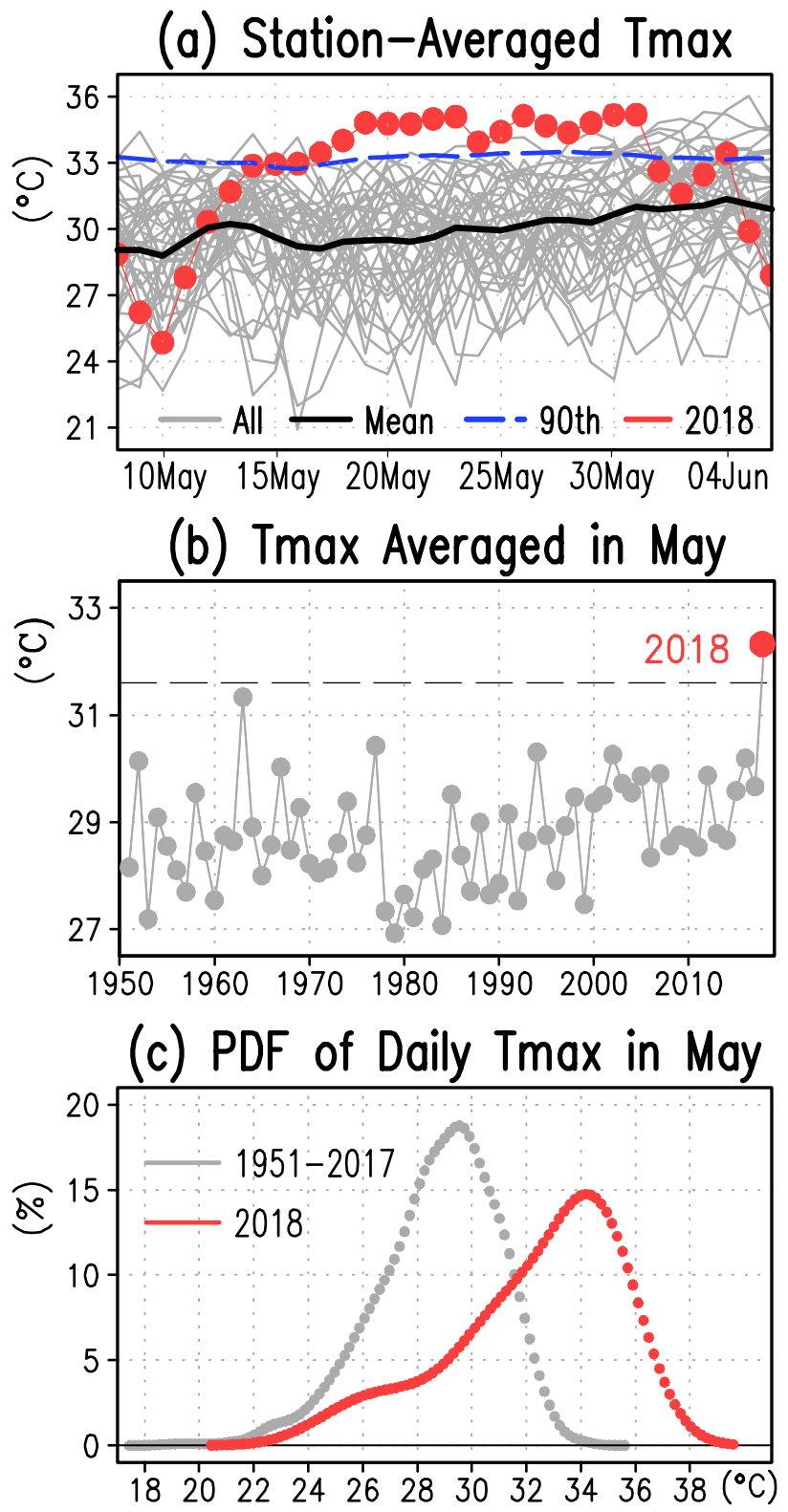

Fig. 2 a $\mathrm{T}_{\max }$ averaged over the 86 stations of each year (grey curves), daily climatology (black), daily 90th-percentile threshold (blue), and 2018 (red). b Time series of monthly Tmax averaged over the 86 stations in May of 1951-2018. c Probability density function (PDF) of Tmax in May of 1951-2017 (grey) and of 2018 alone (red)

recent decades. More interestingly, the Tmax in May 2018 was unprecedentedly large compared to those over the past half a century, suggesting unusually hot May in SC. Figure $2 \mathrm{c}$ shows the probability density function (PDF) of daily Tmax during May, which is used to estimate the likelihood of Tmax above specific temperatures. We find that the mean Tmax shifted from $30{ }^{\circ} \mathrm{C}$ during 1951-2017 to $34{ }^{\circ} \mathrm{C}$ in 2018 . During $1951-2017$, the probability of Tmax above $34{ }^{\circ} \mathrm{C}$ was nearly zero. However, During May 2018, the probability of Tmax exceeding $34{ }^{\circ} \mathrm{C}$ reached 
$50 \%$, implying that the probability of SC heat wave during May 2018 increased substantially.

\subsection{Delayed onset of SCSSM}

Figure 3 presents the meteorological variables associated with the SCSSM. The onset date of the SCSSM is determined by the day when zonal winds over the central SCS shift from easterlies to westerlies and last for more than three consecutive days. As seen from Fig. 3a, the onset of the SCSSM occurs on 15 May on average. Nevertheless, in 2018 the onset appeared in early-June, about three pentads later than the climatology. Accompanied with a delayed-onset of the SCSSM, the rainfall over Guangdong Province changed a lot during May and June 2018. As shown in Fig. 3b, both the rainfall amount and rainfall frequency over Guangdong Province increased considerably since 1 June 2018, compared to those in climatology. However, as seen from Fig. 3c, the rainfall in SC during May 2018 was significantly less than normal because of the delayed onset of the SCSSM.

Figure $4 \mathrm{a}, \mathrm{b}$ depict the time-latitude distributions of 850$\mathrm{hPa}$ horizontal winds and specific humidity in climatology and in 2018, respectively, averaged along the longitude belt of $110^{\circ}-120^{\circ} \mathrm{E}$ (consistent with the SCSSM definition). In climatology, easterly winds prevail over the SCS before mid-May, which shift to westerlies rapidly after 15 May and transport a large amount of water vapor from the SCS to coastal regions of China. In 2018, the atmospheric circulation pattern was quite different. Throughout May 2018, the SCS was overwhelmingly controlled by easterly winds, which started to turn into westerlies in early-June 2018, when a lot of moisture converged over the northern SCS and SC, which could trigger heavy rainfall events in Guangdong Province during early-June 2018. Figure $4 \mathrm{c}$ shows the differences of $850-\mathrm{hPa}$ horizontal winds and specific humidity between 2018 and climatology, where abnormally easterly winds appeared over $0^{\circ}-20^{\circ} \mathrm{N}$ during all the time of May, which effectively hindered the moisture transport from the tropical oceans to $\mathrm{SC}$, leading to a dry environment over the central SCS $\left(0^{\circ}-10^{\circ} \mathrm{N}\right)$ during 1-10 May and over the northern SCS and SC $\left(10^{\circ}-25^{\circ} \mathrm{N}\right)$ during 10-30 May.

Figure $4 \mathrm{~d}-\mathrm{f}$ display the horizontal patterns of $850-\mathrm{hPa}$ winds and specific humidity averaged over 15-31 May. In climatology, strong westerly and southwesterly winds exist over Southeast Asia and the SCS, which brings abundant moisture from the Indian Ocean and the SCS to SC. In 2018, however, an array of easterly winds intruded into the central SCS (Fig. 4e), which acted as a natural barrier that cut off the moisture transport from the tropical oceans to SC, leading to an evident "wet hole" over the northern SCS and SC. The difference map (Fig. 4f) more clearly shows that anomalously easterly winds intruded into the SCS and even into the eastern Indian Ocean during late (a) Index of SCSSM

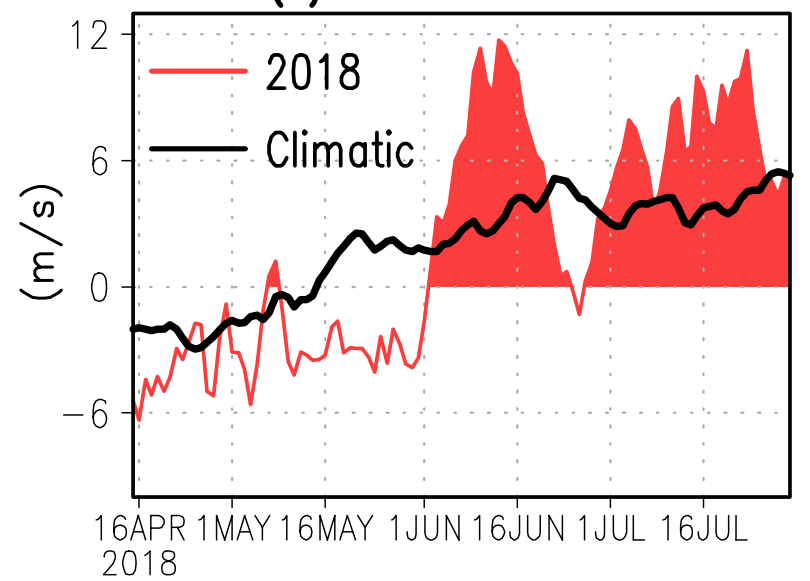

(b) Station-Averaged Roinfall

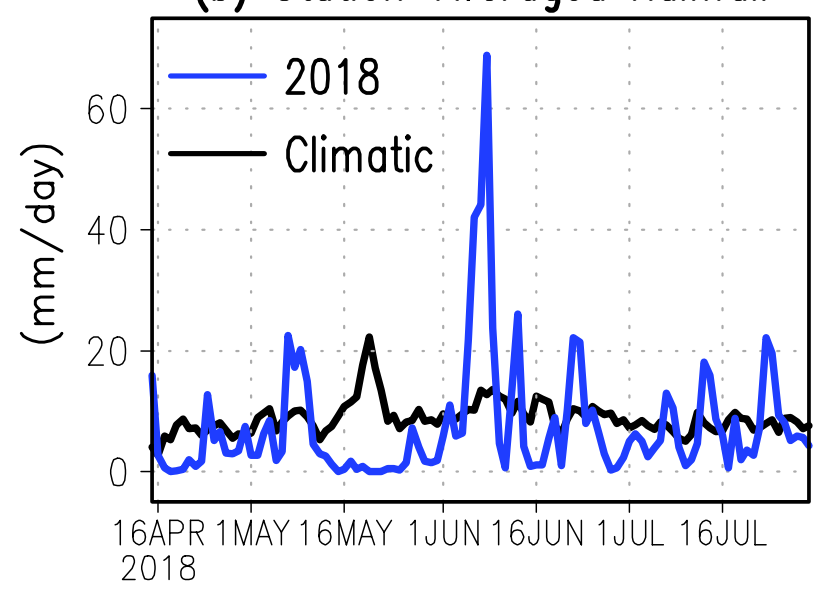

(c) Rainfall Anomaly in May 2018

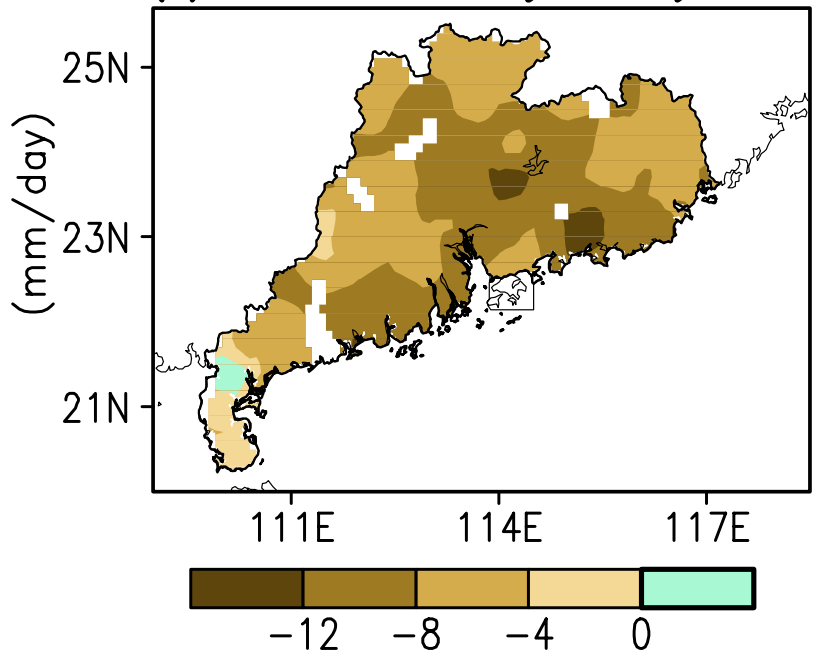

Fig. 3 a Index of South China Sea (SCS) summer monsoon (SCSSM; $\mathrm{m} / \mathrm{s}$ ) in 2018 (red) and in climatology (black). b Evolutions of daily rainfall (mm/day) averaged over the 86 stations in 2018 (blue) and in climatology (black). c Anomalies of rainfall in May 2018 after removing the climatology 


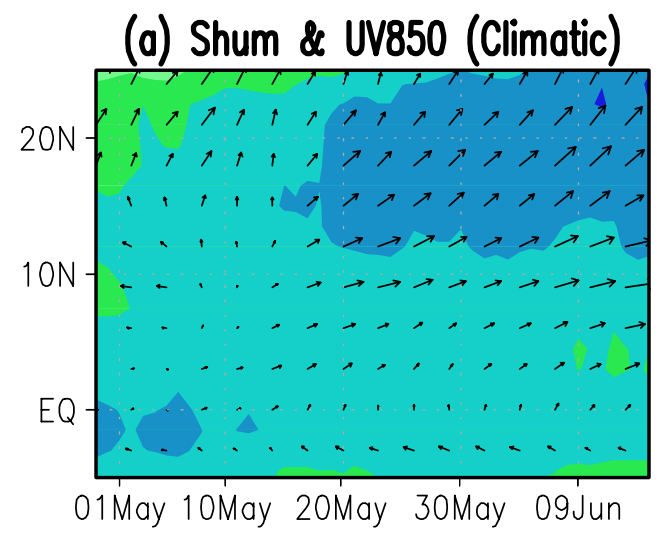

(b) Shum \& UV850 (2018)

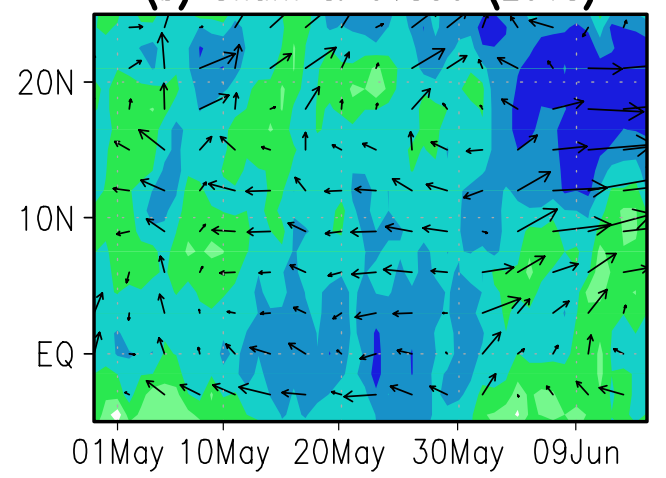

(c) Differences

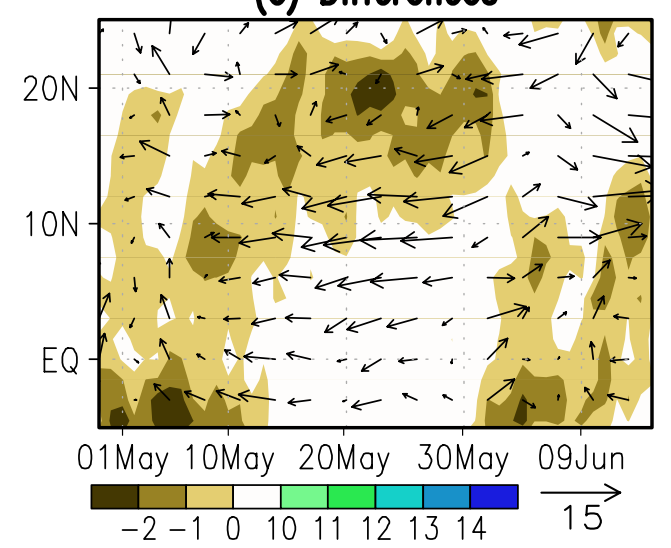

(d) Shum \& UV850 (Climatic)

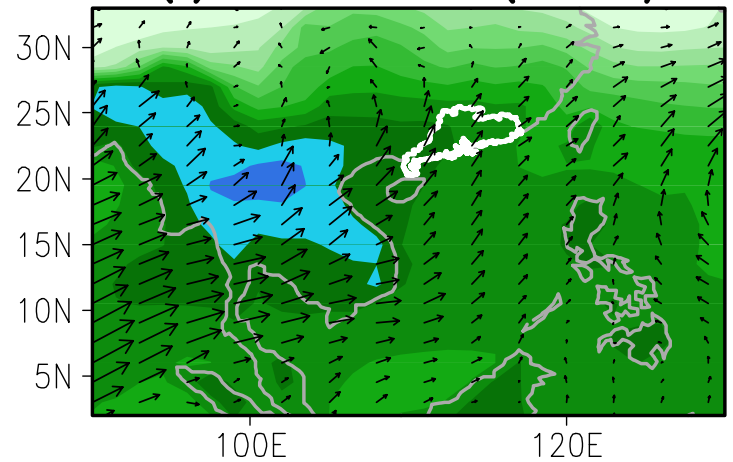

(e) Shum \& UV850 (2018)
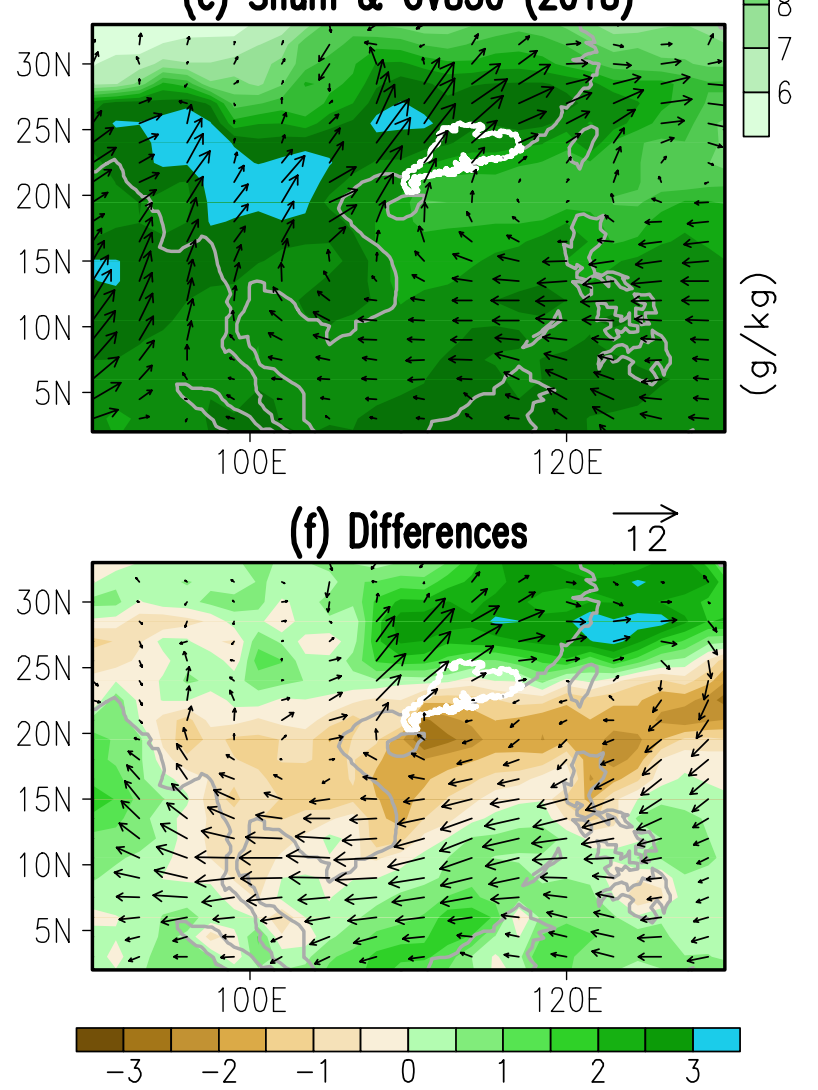

Fig. 4 Specific humidity (shading; g/kg) and 850-hPa winds (vector; $\mathrm{m} / \mathrm{s}$ ) averaged along the longitude band of $110^{\circ}-120^{\circ} \mathrm{E}$ for a climatology, b 2018, and c differences (2018 minus climatology). d-f Similar to a-c, except for the horizontal patterns averaged during 15-31 May 2018

half of May 2018. Meanwhile, anomalously westerly winds appeared over eastern China. The anomalous winds shown in Fig. 4f were actually featured by an anticyclonic anomaly, under which the humidity over the northern SCS and SC decreased apparently so that a dry and hot weather over these regions became more likely. The anomalously dry surface in SC during May 2018 provided a favorable surface environment for SC heat wave.

\section{Mechanisms related to local and remote forcing}

From the above analysis, we learn that the anomalous anticyclone over the SCS and SC played a crucial role in triggering SC extreme heat wave and delaying the onset of the SCSSM. In this section, we discuss the local 
radiation budget and energy conversion associated with SC heat wave. We also try to explain the physical mechanism related to the westward shift of the PSH during May 2018, mainly focusing on the forcing from mid-latitude planetary wave train.

\subsection{Local radiation budget and heat conversion}

Figure 5 shows the anomalies of surface net solar (shortwave) radiation and surface net thermal (longwave) radiation over the SCS and SC during May 2018. The net solar radiation increased consistently in the northern SCS and SC during May 2018 (Fig. 5a), implying that SC obtained more shortwave radiation due to the reduced rainfall and decreased cloud cover under the control of the anomalous anticyclone. Moreover, SC surface emitted more longwave radiation during May 2018 (Fig. 5b) than the climatology, because of the anomalous anticyclone and resultant clear skies over SC. A combination of surface net solar radiation and net thermal radiation yields the surface net radiation. As indicated by Fig. 5c, SC generally had surplus of surface net radiation during May 2018, where the largest change in net radiation could exceed $50 \mathrm{~W} / \mathrm{m}^{2}$. Figure $5 \mathrm{~d}$ presents the daily variations of surface net radiation and Tmax, where the change of net surface radiation matched very well with the change in SC air temperature, suggesting that the gain of surface net radiation be a critical driver for the air temperature and thus SC heat wave.

The surface net radiation could enter the atmosphere through latent and sensible heat fluxes. As shown in Fig. 6a, negative (positive) surface latent heat anomalies were found over SC (the ocean) during May 2018, indicating that there was more (less) latent heat released into the atmosphere due to the longer (shorter) insolation and increased (decreased) evaporation over SC (the ocean). Figure $6 \mathrm{~b}$ illustrates that there was more sensible heat entering the atmosphere during May 2018 than in the climatology, especially in eastern Guangdong Province. The daily variations of the latent and
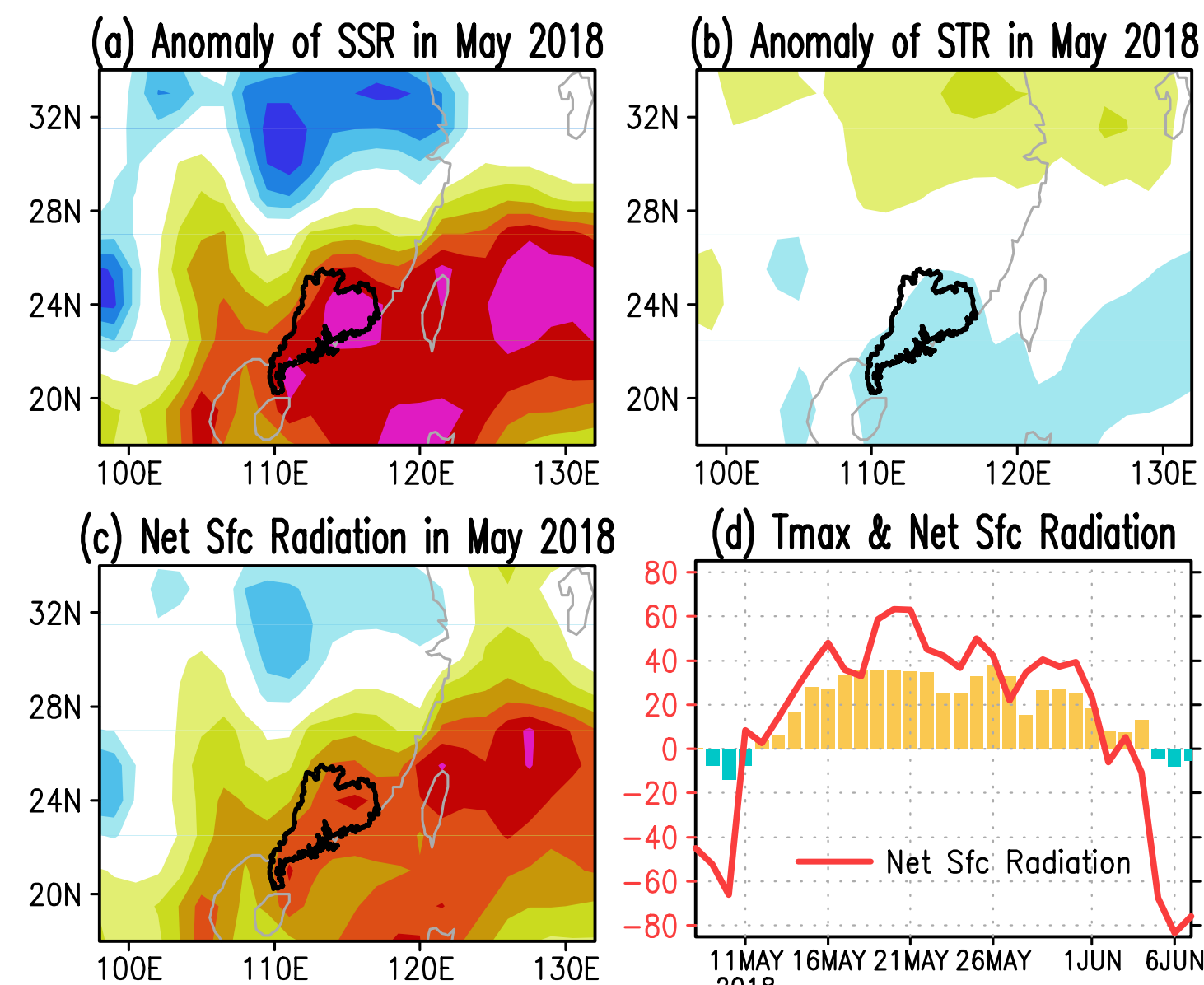

(d) Tmax \& Net Sfc Radiation

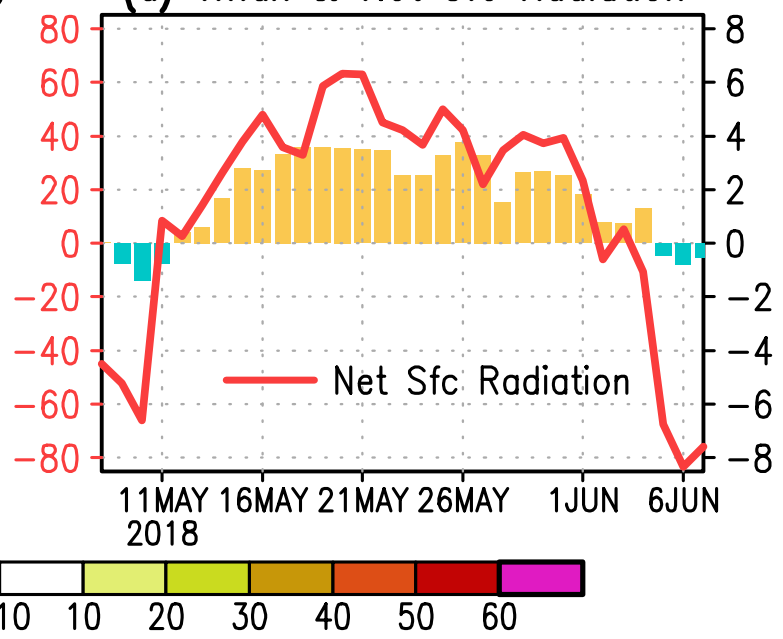

Fig. 5 Anomalies of a surface net solar (shortwave) radiation flux (SSR; w/ $\mathrm{m}^{2}$ ), b surface net thermal (longwave) radiation flux $(\mathrm{STR}$; w/m²), and $\mathbf{c}$ surface net radiation flux $\left(\mathrm{w} / \mathrm{m}^{2}\right)$ that is the sum of SSR and STR. $\mathbf{d}$ Anomalies of averaged $\mathrm{T}_{\max }$ and surface net radiation flux 

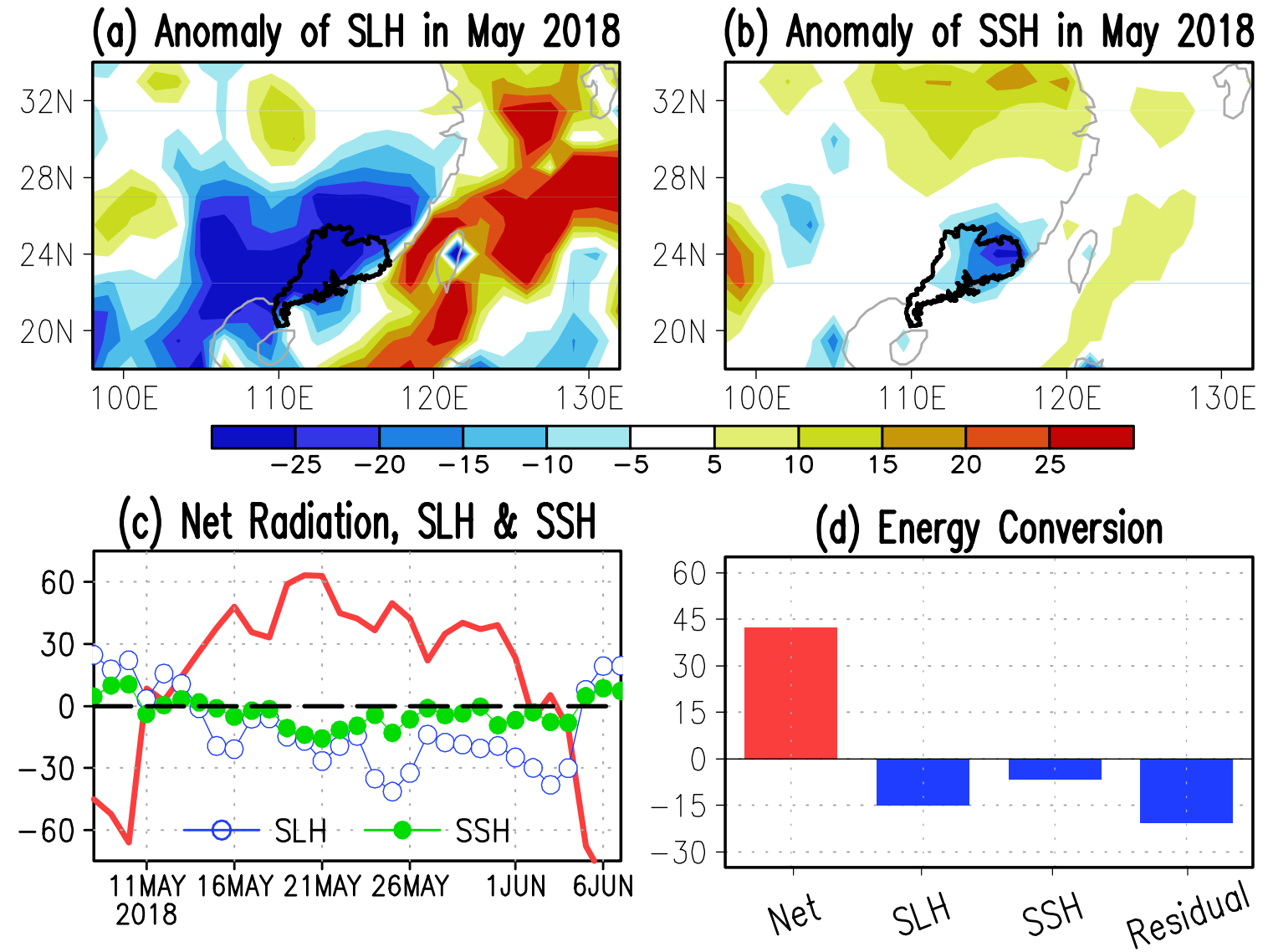

Fig. 6 Anomalies of a surface latent heat flux $\left(\mathrm{SLH} ; \mathrm{w} / \mathrm{m}^{2}\right)$ and $\mathbf{b}$ surface sensible heat flux $\left(\mathrm{SSH} ; \mathrm{w} / \mathrm{m}^{2}\right)$. c Variations of SLH, SSH, and surface net radiation flux. d Energy conversion from surface net radiation flux to SLH and SSH

sensible heat fluxes and their relationships with surface net radiation are shown in Fig. 6c, where the changes in net surface radiation and surface latent/sensible heat fluxes are out of phase during May 2018, which actually reflects a robust energy conversion from net radiation energy to surface heat fluxes. In addition, Fig. $6 \mathrm{~d}$ shows a quantitative analysis on the energy conversion between surface net radiation and surface heat fluxes. The monthly mean net surface radiation flux over SC was nearly $43 \mathrm{~W} / \mathrm{m}^{2}$ in May 2018 , where $15 \mathrm{~W} / \mathrm{m}^{2}$ was converted to the surface latent heat via evaporation and $7 \mathrm{~W} / \mathrm{m}^{2}$ was released into the atmosphere via near-surface turbulences. Overall, there was $50 \%$ of the net radiation flux being converted to the surface heat fluxes, which were finally transformed to the energy fueling SC air temperatures in favor of the heat waves.

\subsection{Physical processes associated with atmospheric teleconnection}

Figure $7 \mathrm{a}, \mathrm{b}$ show the geopotential height at 850 and 500 $\mathrm{hPa}$, respectively, during May. Compared to the climatology, the contour of $1500 \mathrm{gpm}$ during May 2018 covered
Guangdong Province completely, indicating that the PSH experienced a strong westward extension. At $500 \mathrm{hPa}$, the westward displacement of the PSH was more prominent, when the subtropical high encompassed almost the whole SCS, with a high-pressure center over SC and its surrounding regions. Thereby, the anomalous anticyclone and resultant easterly intrusion over the SCS during May 2018 could be intimately associated with the westward extension of the PSH.

Why did the PSH extend westward during May 2018? To answer this question, we survey the global atmospheric circulation anomalies. As shown in Fig. 8a, the westward extension of the PSH during May 2018 was linked to anomalous planetary wave trains in mid-latitude regions, which might appear initially over the North Atlantic and propagated eastward, leading to anomalous high pressures over East Asia and the North Pacific. The anomalous planetary wave trains exhibited a barotropic structure (Fig. 8b, c), with wavenumbers 4 and 5, which fluctuated between 500 and $200 \mathrm{hPa}$. The mid-latitude wave trains mentioned above are similar to the circum-global teleconnection, 

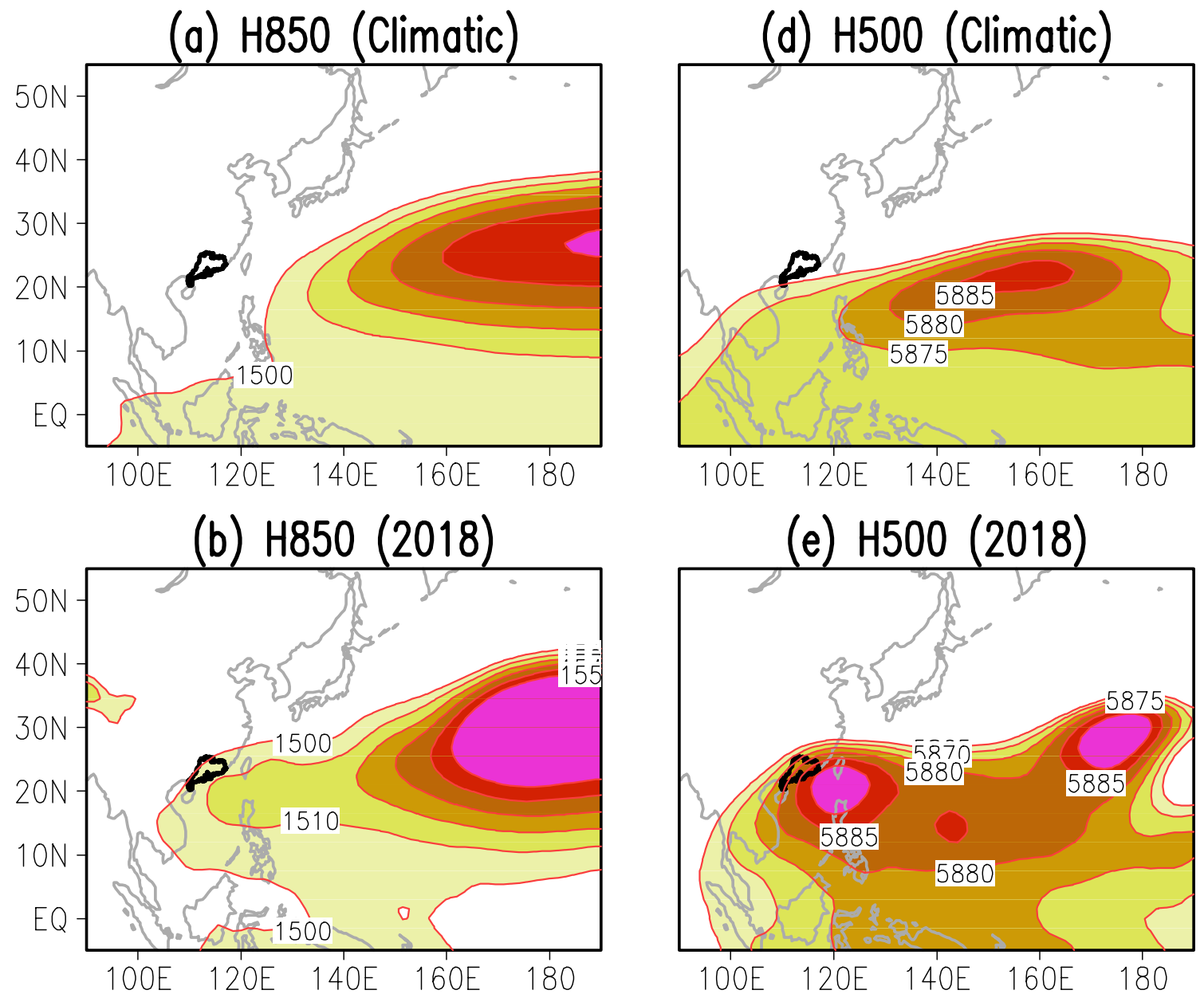

(e) $H 500$ (2018)

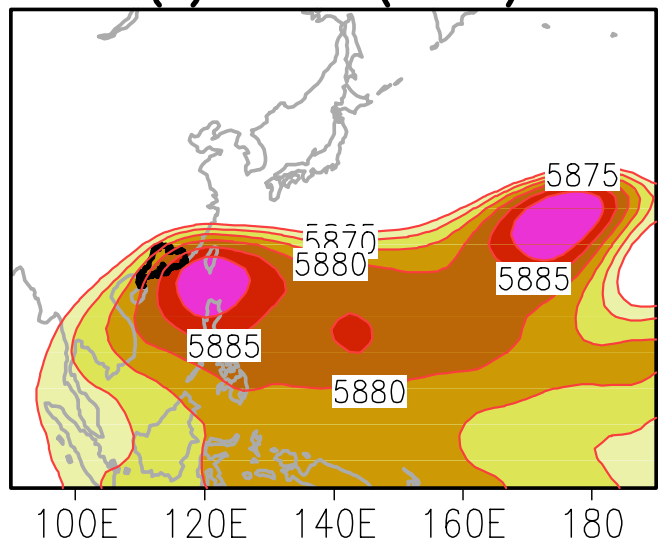

(c) Diffs

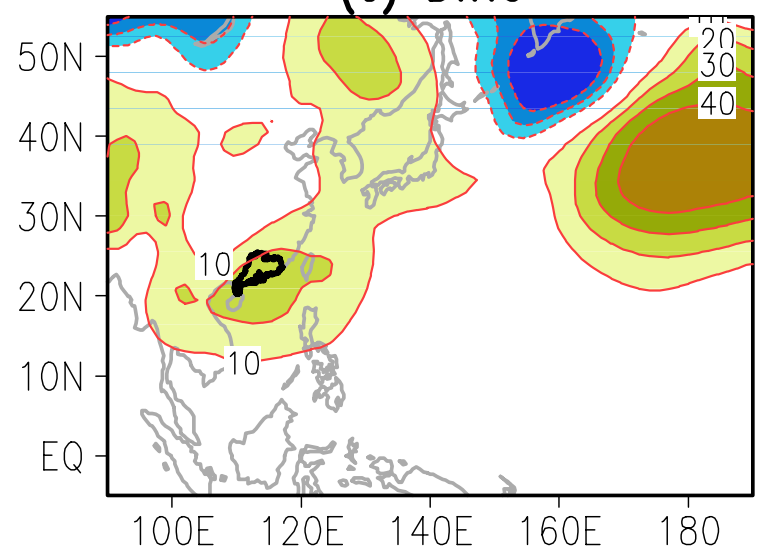

(f) Diffs

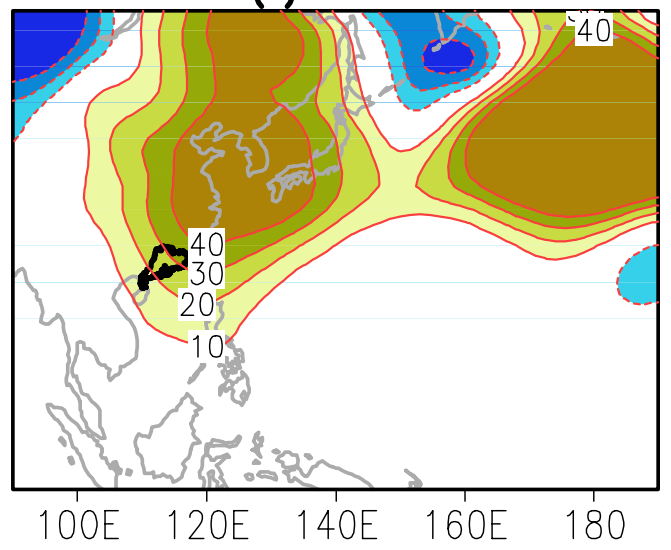

Fig. 7 850-hPa geopotential heights (m) for a climatology, b 2018, c differences (2018 minus climatology). d-f Similar to a-c except for the 500-hPa pressure level. Black bold lines in each subplot mark the location of Guangdong Province

which is believed as an intrinsic variability in the atmosphere (Ding et al. 2005; Ding and Wang 2007).

The above results are for the 2018 case. To examine whether the relationships among SC heat wave, SCSSM, and the PSH are robust, we conduct a composite analysis with respect to the early- and late-onset years of the SCSSM. Figure 9a presents the onset pentads of the SCSSM during 1951-2018, where the onset date is characterized by a large interannual variability. We selected 8 early-onset years (1951, 1966, 1972, 1994, 1996, 2001, 2008, and 2011) when 
Fig. 8 a Anomalies of geopotential height (shading; $\mathrm{m}$ ) and Takaya-Nakamura wave activity flux (vector; $\mathrm{m}^{2} / \mathrm{s}^{2}$ ) at $200 \mathrm{hPa}$. b, c Similar to a, except for the longitude-pressure cross sections along $60^{\circ} \mathrm{N}$ and $40^{\circ} \mathrm{N}$, respectively

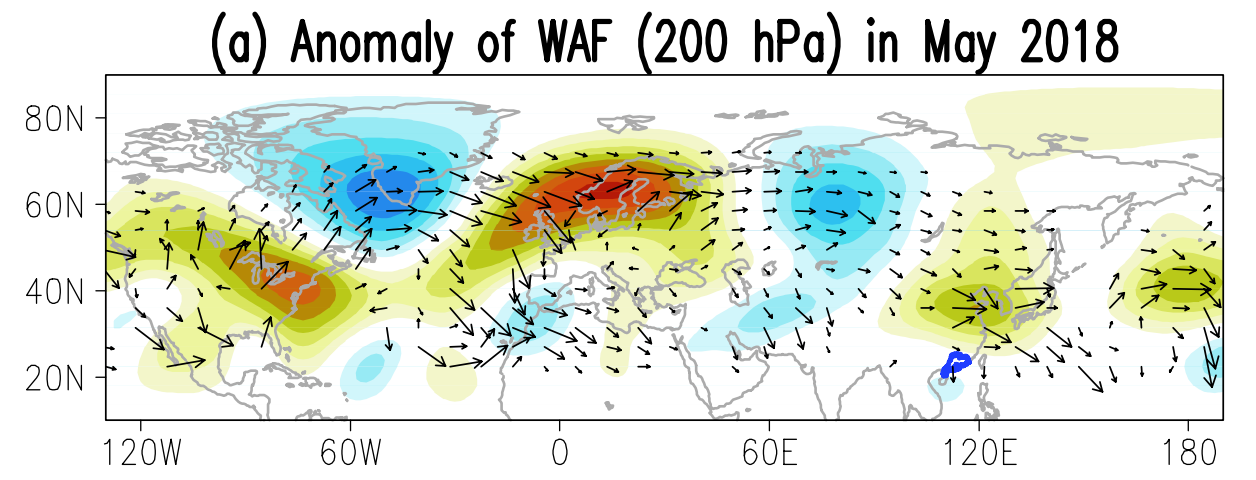

(b) Anomaly of WAF $\left(60^{\circ} \mathrm{N}\right)$ in May 2018

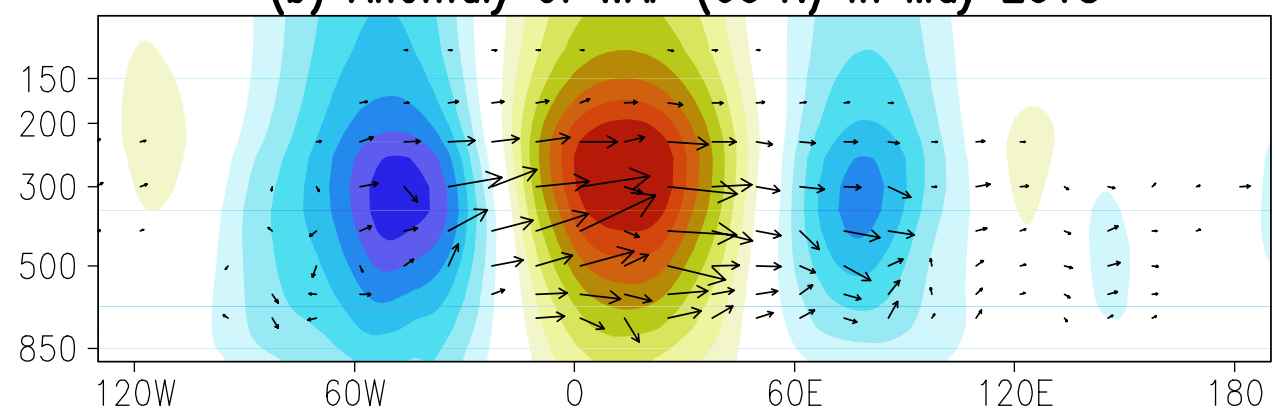

(c) Anomaly of WAF $\left(40^{\circ} \mathrm{N}\right)$ in May 2018

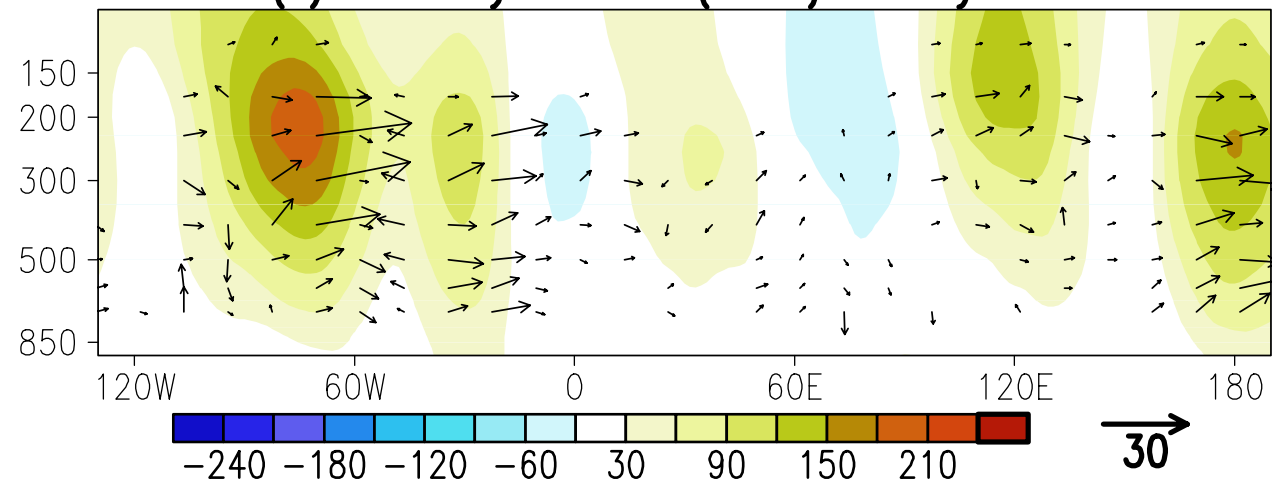

the SCSSM was established in the 26th pentad or earlier, and 12 late-onset years (1954, 1956, 1963, 1970, 1971, 1973, 1982, 1987, 1989, 1991, 2014, and 2018) when the onset occurred in the 31 st pentad or later.

Figure $9 \mathrm{~b}$ displays the probability density function of SC Tmax in May with respective to the early- and late-onset years of the SCSSM. During the early-onset years, the range of SC $\mathrm{T}_{\max }$ is about $20-35{ }^{\circ} \mathrm{C}$, where the probability of Tmax exceeding $35{ }^{\circ} \mathrm{C}$ was approximately zero. During the late-onset years, however, the range of $\mathrm{SC}_{\text {max }}$ is apparently wider, spanning between 15 and $40{ }^{\circ} \mathrm{C}$. The probability of $\mathrm{SC} \mathrm{T}_{\max }$ above $35{ }^{\circ} \mathrm{C}$ is as high as $5 \%$ during the lat-onset years, indicating an enormous increase in the chance of SC heat wave. It is interesting that the variance of SC $\mathrm{T}_{\max }$ during the late-onset years is obviously bigger than that in the early-onset years, while the changes in mean temperature is relatively small between the two periods. In other words, compared to the change in mean air temperature, the delayed SCSSM is more likely to increase the probability of SC heat wave through amplifying the temperature variance in SC.

Figure $9 \mathrm{c}$ displays the differences of $850-\mathrm{hPa}$ geopotential height with respective to the late- and early-onset years of the SCSSM. As can be seen the anomalously low pressure appeared over central and northern China and anomalously high pressure existed over SC and the coastal seas. It should be emphasized that SC is located just in the transition zone between high- and low-pressure anomaly centers, where the surface pressure gradient is the biggest. Thus, the climate and weathers in such region is quite unstable, and any disturbances such as temperature fluctuation will be amplified. This may partly explain why the SC temperature has a relatively larger variance during the years of delayed SCSSM. 


\section{(a) Onset Pentad of SCSSM}

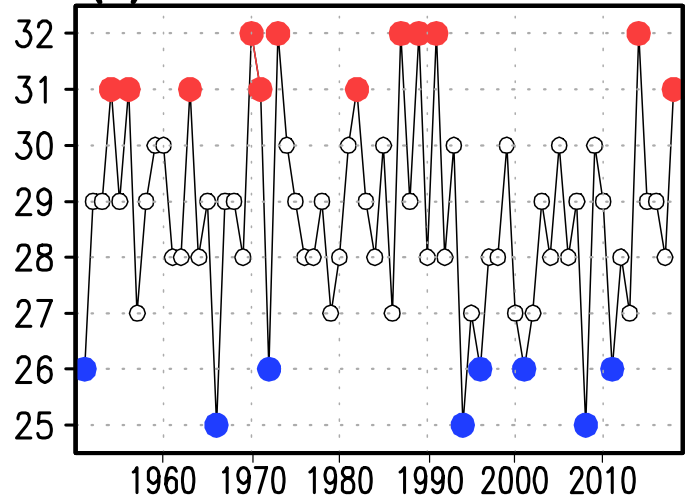

(b) PDF of Tmax in May
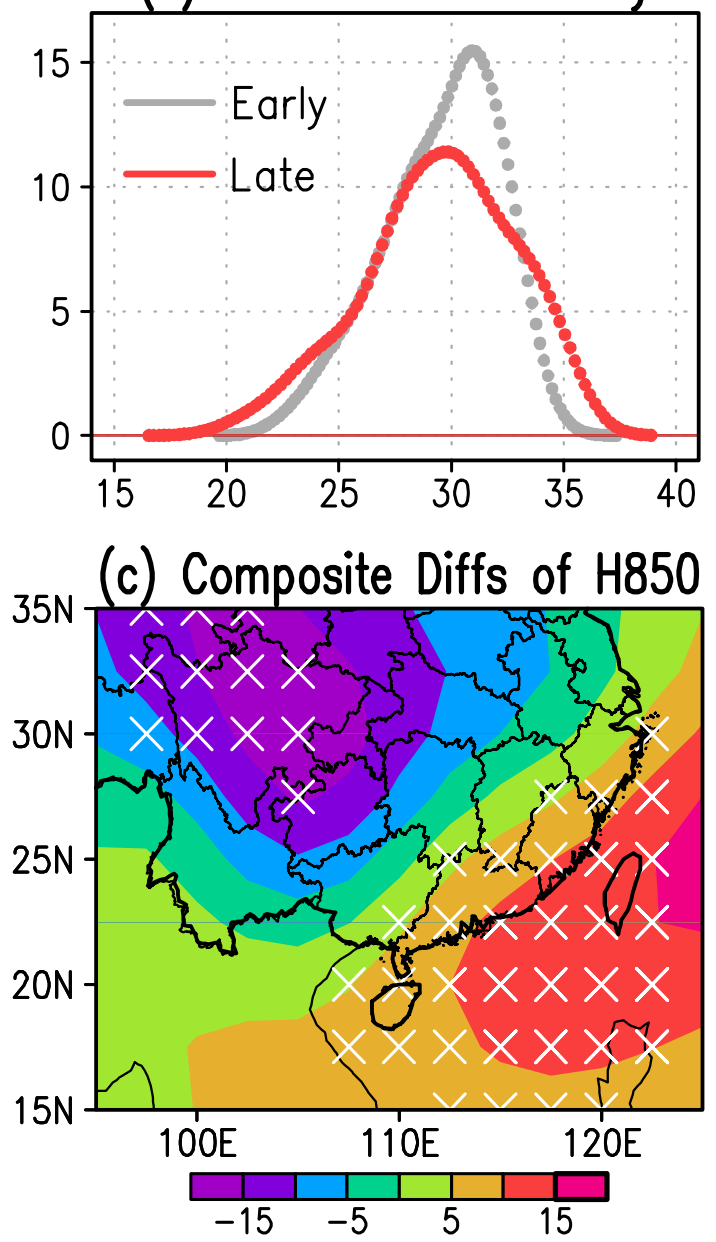

Fig. 9 a Onset pentads of SCSSM during 1951-2018. The blue markers indicate early-onset years, while the red markers denote the lateonset years. b Probability density function (\%) of daily Tmax in SC in May for early-onset (grey) and late-onset (red) years. c Composite differences of $\mathrm{H} 850$ between late and early onset years of SCSSM (late minus early). Crosses indicate that the anomalies exceeding the 95\% confidence level (a) SCSSM \& PSH

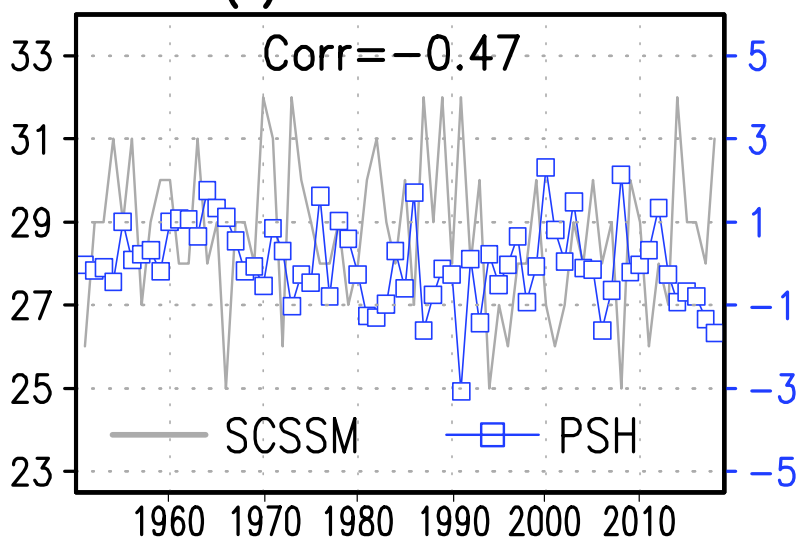

(b) Corr btw H850 \& (-1)*PSH

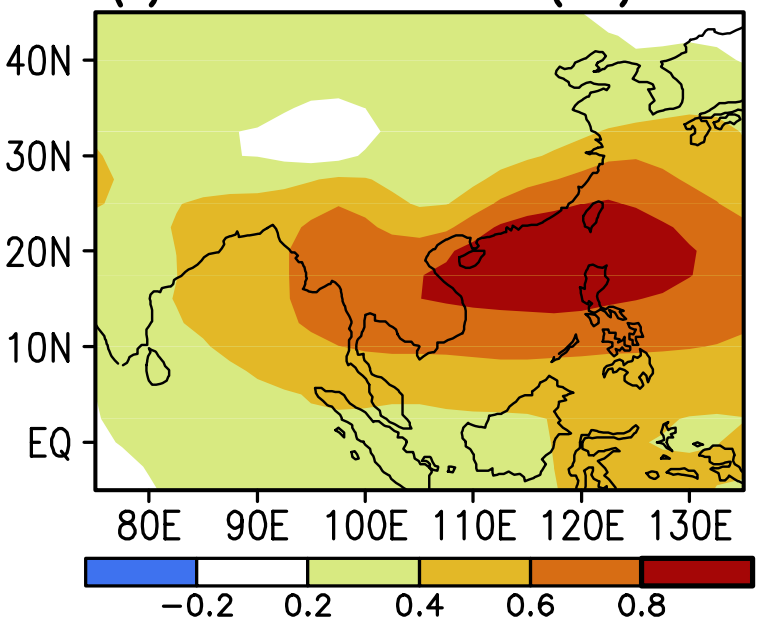

(c) Corr btw Air Temp \& (-1)*PSH

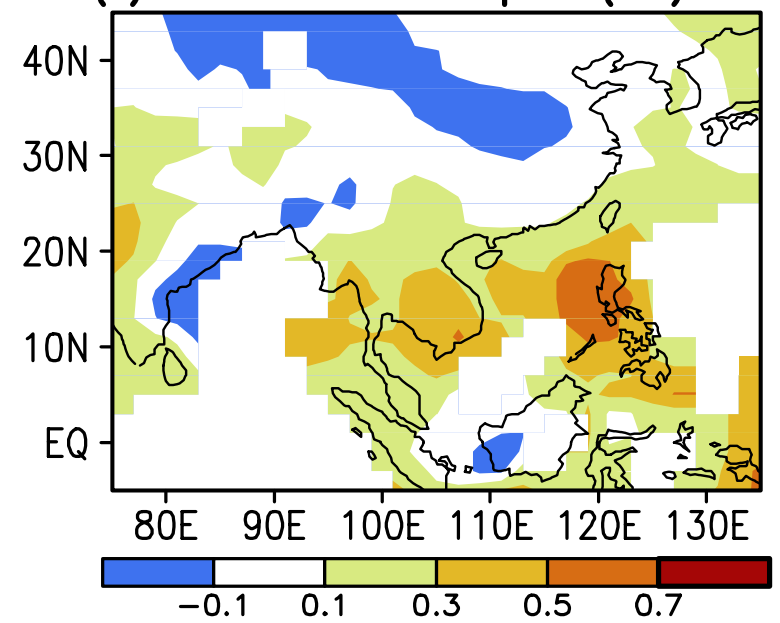

Fig. 10 a SCSSM onset pentads and normalized location index of PSH during 1951-2018. b Correlations between H850 and reversed PSH index. $\mathbf{c}$ Similar to b, except for surface air temperature 
The statistical relationship between SCSSM onset and the PSH is examined using regression/correlation analysis. As shown in Fig. 10a, negative correlation exists between SCSSM onset and the zonal displacement of the PSH, with a correlation coefficient of -0.47 for the period of 1951-2018, exceeding the 99\% confidence level. That is, the westward extension (eastward retreat) of the PSH corresponds to a late onset (early onset) of the SCSSM, which is consistent with the above analysis. Figure 10b, c display the spatial pattern of correlations between H850/surface air temperature and the PSH index, where the westward shift of the PSH is significantly correlated with strengthened pressure and high air temperatures over the northern SCS and SC. The correlation results indicate that the westward

(a) Reg. H500 (Jan)

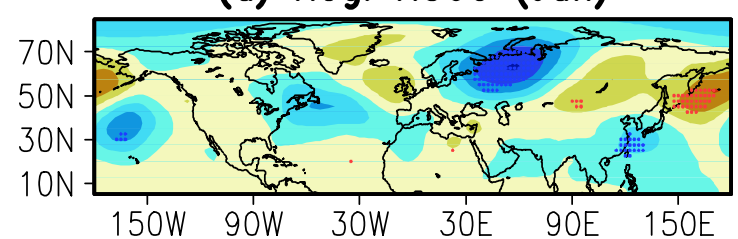

(b) Reg. H50O (Feb)

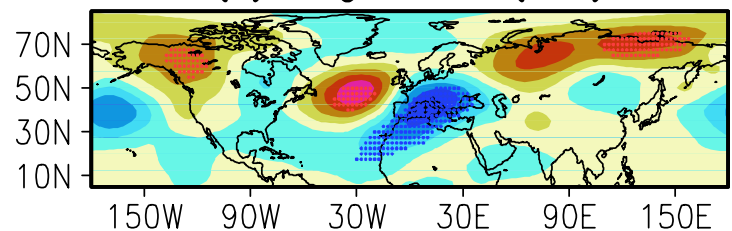

(c) Reg. H50O (Mar)

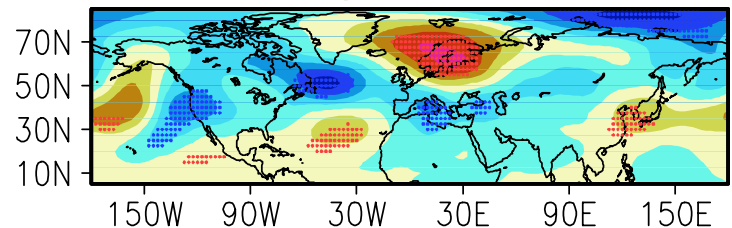

(d) Reg. H500 (Apr)

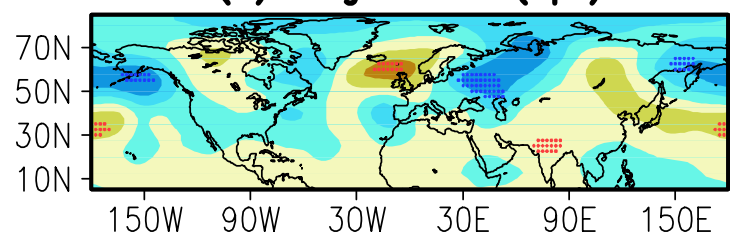

(e) Reg. H50O (May)

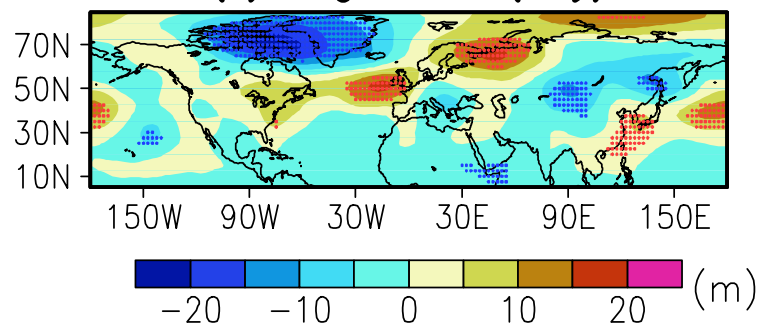

displacement of the PSH would intensify the pressure over the northern SCS and SC and promote an intrusion of easterly winds over the central SCS, which directly lead to the delayed onset of the SCSSM and higher probability of SC heat wave.

Finally, Fig. 11 shows the lag regressions of H500 and SST onto the SCSSM onset index, from which we can explore the global climate variability associated with the SCSSM. From the regressed patterns of atmospheric circulation, we can see that the most obvious signals appear over the mid-latitude regions, where anomalous planetary wave trains are observed over the North Atlantic and Eurasia, reminiscent of the so-called circum-global teleconnection. More importantly, the anomalous wave trains over the upstream

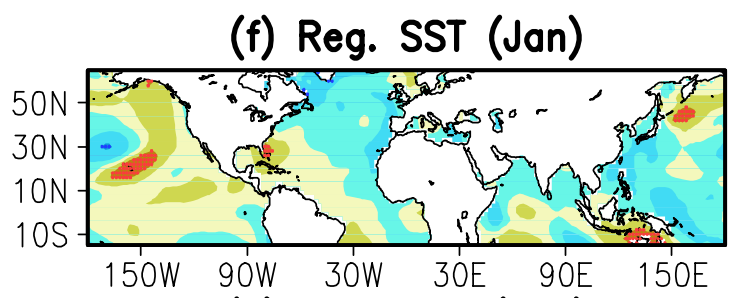

(g) Reg. SST (Feb)

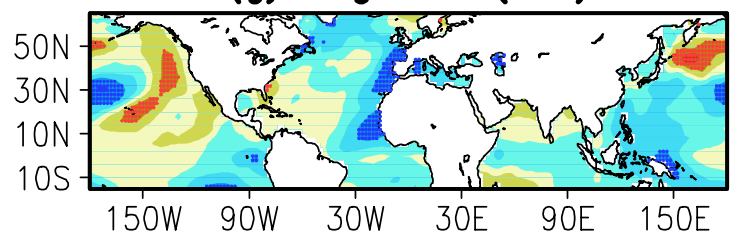

(h) Reg. SST (Mar)

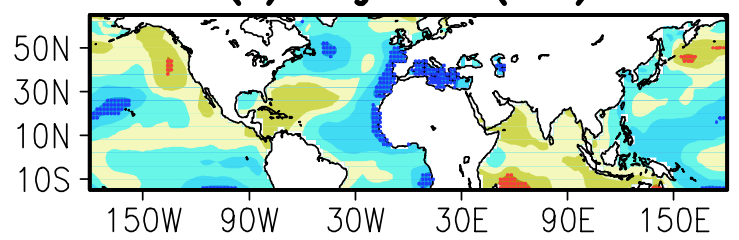

(i) Reg. SST (Apr)

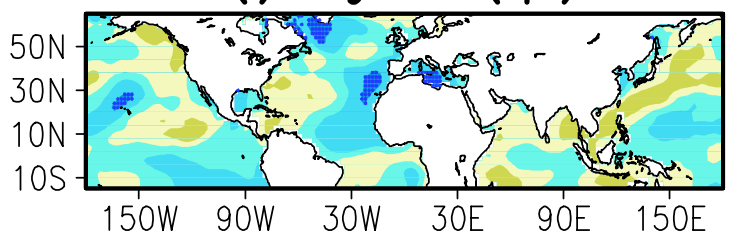

(j) Reg. SST (May)

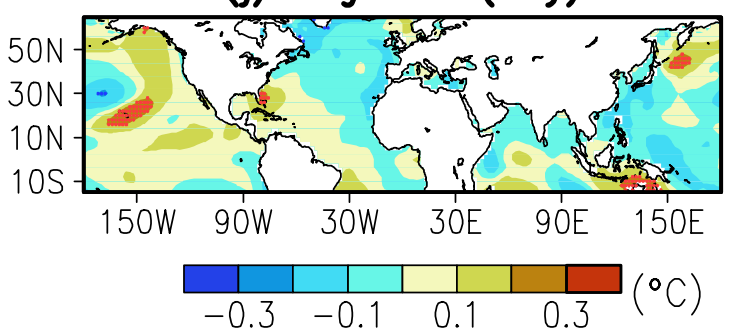

Fig. 11 a Lag regressions of H500 (left) and SST (right) onto the SCSSM onset index. Stippling indicates that the anomalies exceeding the 95\% confidence level 
exist not only in the simultaneous regression but also in the lag regressions. Starting from March, anomalous high pressure is found over East Asia, which is linked to alternative high- and low-pressure centers over the upstream regions. The location and intensity of the wave trains change slightly in April due to the evolution in mean basic state. In May, the anomalous wave trains become more prominent, with lowpressure anomalies appearing over Greenland and Central Asia, while high-pressure anomalies occur over Europe and East Asia, causing the westward extension of the PSH and delayed SCSSM. Compared to the atmospheric circulation, the SST anomalies (SSTAs) related to the SCSSM seem to be less significant. In the tropical regions, positive SSTAs are primarily found around the Maritime Continent, as discussed previously (Zhou et al. 2009), where the warm SSTAs may enhance the warm pool convection and hinder the establishment of the SCSSM by inducing descending motions over the off-equator regions. In the extratropics, significant SSTAs appear in the North Pacific and North Atlantic, which are more likely the responses to the atmosphere rather than drivers, given that the mid-latitude SST during boreal spring is insufficient to trigger deep convection. Therefore, the midlatitude atmospheric planetary wave trains, which could be an intrinsic variability of the atmosphere, play a critical role in linking the upstream climate variability to the changes in PSH, SCSSM onset, and SC heat wave.

\section{Summary}

In this study, we investigate a record-breaking heat wave in $\mathrm{SC}$, and explore their relationships with delayed onset of the SCSSM and the westward shift of the PSH. We show that the delayed onset of SCSSM could block the transport of water vapor from tropical oceans to SC, leading to decreased rainfall, longer insolation, and drier surface condition over $\mathrm{SC}$, favoring the occurrence of SC heat wave.

Both SC heat wave and the delayed onset of the SCSSM are significantly affected by the westward extension of the PSH. The correlation coefficient between SCSSM onset and the PSH index is -0.47 during 1951-2018, indicating that the westward extension (eastward retreat) of the PSH is significantly correlated with a delayed onset (early onset) of the SCSSM. The westward displacement of the PSH would intensify and promote the intrusion of easterly winds over the central SCS, leading to the delayed onset of the SCSSM. Moreover, an anomalous anticyclone appeared over the northern SCS and SC in 2018 due to the delayed onset of the SCSSM and the westward extension of the PSH. As a result, SC obtained increased surface net radiation, which was released into the atmosphere via surface latent and sensible heat fluxes.
Finally, we illustrate that the delayed onset of the SCSSM and the westward extension of the PSH are significantly correlated with mid-latitude planetary wave trains. Based on the lag regression analysis, we reveal that the planetary wave train exhibited prominent intra-seasonal variability, which could be used to improve the seasonal prediction for East Asian climate and weathers during the boreal spring.

Acknowledgements We thank the Guangzhou Institute of Tropical and Marine Meteorology, CMA, for providing the daily station data. This study was supported by the National Key Research and Development Program of China (Grants 2018YFC1505801 and 2016YFA0602703), the National Natural Science Foundation of China (Grants 41690123, 41690120, and 91637208), Sichuan Science and Technology Program (Grant 2018JY0030) and the CMA Guangzhou Joint Research Center for Atmospheric Sciences.

Open Access This article is licensed under a Creative Commons Attribution 4.0 International License, which permits use, sharing, adaptation, distribution and reproduction in any medium or format, as long as you give appropriate credit to the original author(s) and the source, provide a link to the Creative Commons licence, and indicate if changes were made. The images or other third party material in this article are included in the article's Creative Commons licence, unless indicated otherwise in a credit line to the material. If material is not included in the article's Creative Commons licence and your intended use is not permitted by statutory regulation or exceeds the permitted use, you will need to obtain permission directly from the copyright holder. To view a copy of this licence, visit http://creativecommons.org/licenses/by/4.0/.

\section{References}

Chen R, Wen Z, Lu R (2018) Large-scale circulation anomalies and intraseasonal oscillations associated with long-lived extreme heat events in South China. J Clim 31:213-232. https://doi. org/10.1175/JCLI-D-17-0232.1

Coumou D, Rahmstorf S (2012) A decade of weather extremes. Nat Climate Change 2:491-496. https://doi.org/10.1038/nclimate1452

Dee D et al (2011) The ERA-Interim reanalysis: configuration and performance of the data assimilation system. Q J R Meteorol Soc 137:553-597. https://doi.org/10.1002/qj.828

Deng KQ, Ting MF, Yang S, Tan YH (2018a) Increased frequency of summer extreme heat waves over Texas area tied to the amplification of pacific zonal SST gradient. J Clim 31:5629-5647. https:// doi.org/10.1175/JCLI-D-17-0554.1

Deng KQ, Yang S, Ting MF, Lin A, Wang Z (2018b) An intensified mode of variability modulating the summer heat waves in eastern Europe and northern China. Geophys Res Lett 45:11361-11369. https://doi.org/10.1029/2018GL079836

Deng KQ, Yang S, Lin AL, Li CH, Hu CD (2019a) Unprecedented East Asian warming in spring 2018 linked to the North Atlantic tripole SST mode. Atmos Ocean Sci Lett 12:246-253. https://doi. org/10.1080/16742834.2019.1605807

Deng KQ, Yang S, Ting MF, Zhao P, Wang ZY (2019b) Dominant modes of China summer heat waves driven by global sea surface temperature and atmospheric internal variability. J Clim 32:37613775. https://doi.org/10.1175/JCLI-D-18-0256.1

Ding QH, Wang B (2005) Circumglobal teleconnection in the Northern Hemisphere summer. J Clim 18:3483-3505. https://doi. org/10.1175/JCLI3473.1 
Ding QH, Wang B (2007) Intraseasonal teleconnection between the summer Eurasian wave train and the Indian monsoon. J Clim 20:3751-3767. https://doi.org/10.1175/JCLI4221.1

Ding YH, Li CY, Liu JY (2004) Overview of the South China Sea monsoon experiment. Adv Atmos Sci 21:343-360. https://doi. org/10.1007/BF02915563

Huang B et al (2015) Extended reconstructed sea surface temperature version 4 (ERSST.v4). Part I: Upgrades and intercomparison. J Clim 28:911-930. https://doi.org/10.1175/JCLI-D-14-00006.1

Kajikawa Y, Wang B (2012) Interdecadal change of the South China Sea summer monsoon onset. J Clim 25:3207-3218. https://doi. org/10.1175/JCLI-D-11-00207.1

Kalnay E, Coauthors (1996) The NCEP/NCAR 40-year reanalysis project. Bull Am Meteor Soc 77:437-471. https://doi. org/10.1175/1520-0477(1996)077<0437:TNYRP>2.0.CO;2

Li ZN, Yang S, He B, Hu CD (2016) Intensified springtime deep convection over the South China Sea and the Philippine Sea dries southern China. Sci Rep 6:30470. https://doi.org/10.1038/srep3 0470

Liu B, Zhu C (2019) Extremely late onset of the 2018 South China Sea summer monsoon following a La Niña event: effects of triple SST anomaly mode in the North Atlantic and a weaker Mongolian cyclone. Geophys Res Lett 46:2956-2963. https://doi. org/10.1029/2018GL081718

Lu R (2002) Indices of the summertime western North Pacific subtropical high. Adv Atmos Sci 19:1004-1028. doi:https://doi. org/10.1007/s00376-002-0061-5

Luo M, Lau NC (2018) Synoptic characteristics, atmospheric controls, and long-term changes of heat waves over the Indochina Peninsula. Clim Dyn 51:2707-2723. https://doi.org/10.1007/s0038 2-017-4038-6

Meehl GA, Tebaldi C (2004) More intense, more frequent, and longer lasting heat waves in the 21st century. Science 305:994-997. https ://doi.org/10.1126/science.1098704

Sun J, Wang H, Wei W (2011) Decadal variability of the extreme hot event in China and its association with atmospheric circulations. Clim Environ Res 16:199-208. https://doi.org/10.3878/j. issn.1006-9585.2011.02.09 (in Chinese)

Takaya K, Nakamura H (2001) A formulation of a phase-independent wave-activity flux for stationary and migratory quasigeostrophic eddies on a zonally varying basic flow. J Atmos Sci 58:608-627. https://doi.org/10.1175/1520-0469(2001)058<0608:AFOAP $\mathrm{I}>2.0 . \mathrm{CO} ; 2$

Wang B, Lin H, Zhang Y, Lu MM (2004) Definition of South China Sea monsoon onset and commencement of the East Asia summer monsoon. J Clim 17:699-710. https://doi.org/10.1175/2932.1

Wang W, Zhou W, Chen D (2013) Summer high temperature extremes in Southeast China: Bonding with the El Nino-southern Oscillation and East Asian summer monsoon coupled system. J Clim 27:4122-4138. https://doi.org/10.1175/JCLI-D-13-00545.1

Wang ZY, Liu YJ, Ding T, Li D, Hong JL (2018) Features and possible causes for the climate anomalies in spring 2018. Meteor Mon 44:1360-1369. https://doi.org/10.7519/j.issn.10000526.2018.10.013 (In Chinese)

Yang H, Sun SQ (2005) The characteristics of longitudinal movement of the subtropical high in the western Pacific in the pre-rainy season in South China. Adv Atmos Sci 22:392-400. https://doi. org/10.1007/BF02918752

Yang RW, Xie ZA, Cao J (2017) A dynamic index for the westward ridge point variability of the Western Pacific subtropical high during summer. J Clim 30:3325-3341. https://doi.org/10.1175/ JCLI-D-16-0434.1

Zhang F, He LF (2018) Analysis of the June 2018 atmospheric circulation and weather. Meteor Mon 44:1237-1244. https://doi. org/10.7519/j.issn.1000-0526.2018.09.012

Zhang FH, Tao YW, Gao H, Chen T (2019) Persistent extreme high temperature event in southern China in late spring of 2018 and the effect of Madden-Julian Oscillation. Chinese J Atmos Sci 42:100-108. https://doi.org/10.13878/j.cnki.dakxxb.2018092800 (In Chinese)

Zhou TJ et al (2009) Why the western Pacific subtropical high has extended westward since the late 1970 s. J Clim 22:2199-2215. https://doi.org/10.1175/2008JCLI2527.1

Publisher's Note Springer Nature remains neutral with regard to jurisdictional claims in published maps and institutional affiliations. 